Article

\title{
Targeted Gene Knockin in Porcine Somatic Cells Using CRISPR/Cas Ribonucleoproteins
}

\author{
Ki-Eun Park $1,2,3,+$, Chi-Hun Park ${ }^{1,2, \dagger}$, Anne Powell ${ }^{2, \dagger}{ }^{+}$Jessica Martin ${ }^{1,2}$, David M. Donovan ${ }^{2}$ \\ and Bhanu P. Telugu 1,2,3,* \\ 1 Department of Animal and Avian Sciences, University of Maryland, College Park, MD 20742, USA; \\ kepark@umd.edu (K.-E.P.); chpark@umd.edu (C.-H.P.); jjm11393@umd.edu (J.M.) \\ 2 Animal Bioscience and Biotechnology Laboratory, USDA-ARS, Beltsville, MD 20705, USA; \\ anne.powell@ars.usda.gov (A.P.); david.donovan@ars.usda.gov (D.M.D.) \\ 3 Livestock Genomix, Reisterstown, MD 21136, USA \\ * Correspondence: btelugu@umd.edu; Tel.: +1-301-504-5295 \\ + These authors contributed equally to this work.
}

Academic Editor: Izuho Hatada

Received: 1 May 2016; Accepted: 19 May 2016; Published: 26 May 2016

\begin{abstract}
The pig is an ideal large animal model for genetic engineering applications. A relatively short gestation interval and large litter size makes the pig a conducive model for generating and propagating genetic modifications. The domestic pig also shares close similarity in anatomy, physiology, size, and life expectancy, making it an ideal animal for modeling human diseases. Often, however, the technical difficulties in generating desired genetic modifications such as targeted knockin of short stretches of sequences or transgenes have impeded progress in this field. In this study, we have investigated and compared the relative efficiency of CRISPR/Cas ribonucleoproteins in engineering targeted knockin of pseudo attP sites downstream of a ubiquitously expressed COL1A gene in porcine somatic cells and generated live fetuses by somatic cell nuclear transfer (SCNT). By leveraging these knockin pseudo attP sites, we have demonstrated subsequent phiC31 integrase mediated integration of green fluorescent protein (GFP) transgene into the site. This work for the first time created an optimized protocol for CRISPR/Cas mediated knockin in porcine somatic cells, while simultaneously creating a stable platform for future transgene integration and generating transgenic animals.
\end{abstract}

Keywords: CRISPR/Cas; SCNT; cloning; knockin; TARGATT pig; transegenic

\section{Introduction}

The pig is an important dual purpose animal model for agriculture and biomedical applications. With an increasing global population and an increased demand for animal protein, domesticated animals such as pigs are critical for tackling the emerging global food security crisis. Unlike domestic ruminants, the pig has a short gestational interval (114 days), is a litter bearing animal carrying an average of 14 piglets in one pregnancy, and in commercial setting can give rise to three pregnancies in one year. These attributes make it not only a valuable model for agriculture but also for genetic engineering applications, where relatively short pregnancy and large litter size is preferred for generating and propagating genetically modified animals. From a biomedical standpoint, there is an increased awareness among the biomedical community that mouse models cannot meet the complete spectrum of biomedical needs, and an alternative animal model such as the pig is required to meet the shortcomings of the mouse model [1-5].

In domestic pigs, the preferred means for generating genetically engineered animals is somatic cell nuclear transfer (SCNT), where somatic cells typically fetal fibroblasts are modified to include the intended genetic modification and used as nuclear donors for generating genetically modified 
offspring. The most common genetic modification is transgenesis, where the transgene of interest is introduced into somatic cells and selected for stable integration of the transgene prior to SCNT. However, random integration of transgenes suffers from potential limitations such as insertional mutagenesis (the transgene inserts into an existing gene potentially disrupting the endogenous gene's expression or function), lack of control over transgene copy number, silencing or aberrant expression of transgenes in non-target tissues based on the site of integration (positional variegation), random assortment and segregation in subsequent generations, to name a few [6]. In this regard, inserting the transgenes into a specific locus by gene targeting (knockin) is preferable to avoid the concerns outlined above. However, homologous recombination mediated gene targeting events suffer from poor efficiencies in somatic cells ( 1 in $10^{6}-10^{7}$ cells). An additional limitation with the use of most commonly used somatic cells (fetal fibroblasts) is their limited viability in culture for screening recombinants. Site specific nucleases or genome editors such as ZFNs (zinc finger nucleases), TALENs (transcription activator-like effector nucleases), and CRISPR (clustered regulated interspaced short palindromic repeat) and CRISPR-associated (Cas) nuclease system (CRISPR/Cas) that engineer a double strand break (DSB) at the target site and promote gene targeting or homologous recombination can improve efficiencies by nearly 1000 fold and thus could offer a solution [7].

Among the available editors, the CRISPR/Cas system has emerged as a tool of choice in most laboratories because of the ease of design, assembly, delivery and a high degree of reliable gene modifications. In pigs and other domestic animals, the CRISPR/Cas system has been employed successfully for the generation of edited animals [8-13]. In these studies, a mammalian codon optimized Type III Cas9 from Streptococcus pyogenes alongside a chimeric synthetic single-guide RNA (sgRNA) [14] containing Cas9 binding sites and a $20 \mathrm{nt}$ guide sequence specific to the target site has been used to introduce DSBs $[8,10-12,15]$. The DSBs generated by CRISPRs (and other editors) activate endogenous DNA repair pathways that include a predominant error prone non-homologous end joining (NHEJ) or high fidelity homology directed repair (HDR) pathway. For generating gene ablation models, NHEJ is the preferred pathway, whereas for introducing gene knockins and point mutations, the HDR pathway is preferred. In order to achieve HDR at high frequencies, we sought to test several published options that include: the use of a single stranded oligonucleotide as a targeting template, small molecule inhibitors of DNA ligase IV such as SCR7 [16,17], transient incubation of cells at low temperatures $[18,19]$, and finally, the choice of CRISPR reagents. CRISPR reagents can be delivered as DNA expression vectors, RNA preparations, and most recently a ribonucleoprotein complex of Cas 9 protein and sgRNA. However, there are no published studies in porcine systems so far that have outlined or examined these different reagents in a head to head comparison. In the current study, we sought to demonstrate that it is possible to create site specific knockins of short DNA sequences, specifically pseudo attP sites (50 bp) downstream of a ubiquitously expressed COL1A gene, permitting subsequent phiC31 integrase-mediated introduction of functional transgenes. Serine integrases such as phiC31 integrase cause recombination between two $50 \mathrm{bp}$ recognition sequences attP and attB sites, respectively, and integrate the transgene into the knockin site [20,21]. When such integration takes place site-specifically downstream of a ubiquitously expressed gene, the transgene is expected to be protected from aberrant silencing and positional variegation as outlined above. We correctly hypothesized that a pre-complexed Cas9 protein and sgRNA would be effective in engineering DSBs and facilitating knockin, and that the pseudo attP sites would permit future integration of transgenes into the sites.

\section{Results}

\subsection{Targeted Knockin of Pseudo-attP Sites Downstream of Porcine COL1A Gene in Somatic Cells Using CRISPR/Cas System}

\subsubsection{Influence of Temperature on Colony Formation and HDR Outcome}

Porcine fetal fibroblasts in early passage were nucleofected with plasmids expressing a Cas9:GFP fusion and a sgRNA that targets the COL1A locus, along with a 200 nucleotide (nt) single stranded 
DNA oligonucleotide containing two pseudo attP sites (50 nt each; $100 \mathrm{nt}$ total) and $100 \mathrm{nt}$ overall homology (50 nt on either side of the attP sites). The nucleofected cells were cultured in $10 \%$ fetal calf serum (FCS) supplemented DMEM medium in the presence or absence of DNA ligase IV and NHEJ pathway inhibitor, SCR7 $(10 \mu \mathrm{M} / \mathrm{mL})$ at $30^{\circ} \mathrm{C}$ for three days or $38.5^{\circ} \mathrm{C}$ for one day before sorting. One day after nucleofection, the GFP expressing cells were sorted to yield a single GFP expressing cell/well in a 96-well plate. The sorted cells were cultured in irradiated mouse embryonic feeder conditioned medium (CM) supplemented with $5 \mathrm{ng} / \mathrm{mL}$ fibroblast growth factor 2 (FGF2) at $38.5^{\circ} \mathrm{C}$ in $5 \% \mathrm{CO}_{2}$ and $5 \% \mathrm{O}_{2}$. The colonies that formed following sorting were further sub-cultured in 48-well plate at $38.5^{\circ} \mathrm{C}$ until confluence, when the colonies were counted, collected by trypsin, and genomic DNA isolated for genetic screening. As shown in Figure $1 \mathrm{~A}$ and Table 1, less than 2\% (1.7\%) of the sorted cells established colonies at $30{ }^{\circ} \mathrm{C}$, and inclusion of SCR7 resulting in greater than doubling of colonies established (4.3\%). In the established colonies, approximately $13 \%$ of colonies showed a 100 base pair (bp) shift in the product size suggestive of a knockin of two pseudo attP sites in the COL1A targeting site (that was verified by DNA sequence analysis of an amplicon of this region). Inclusion of SCR7 at $30^{\circ} \mathrm{C}$ resulted in greater than a threefold increase (13\% vs. 44\%) in the percentage of targeted colonies (Table 1). When compared to cultures maintained at $30^{\circ} \mathrm{C}$, incubating the plates at $38.5^{\circ} \mathrm{C}$ resulted in a doubling of the percentage of colonies in both the absence and presence of SCR7 (3.7\% and 10.4\%, respectively) (Figure 1B and Table 1). Interestingly, an increase in the number of colonies at $38.5{ }^{\circ} \mathrm{C}$ resulted in a corresponding increase in the number of targeted colonies in the absence of SCR7 (13\% vs. 57\%, respectively), but not in the presence of SCR7 (44\% in both).

\section{A. Cas9 plasmid + sgRNA plasmid + Oligo at $30^{\circ} \mathrm{C}$}

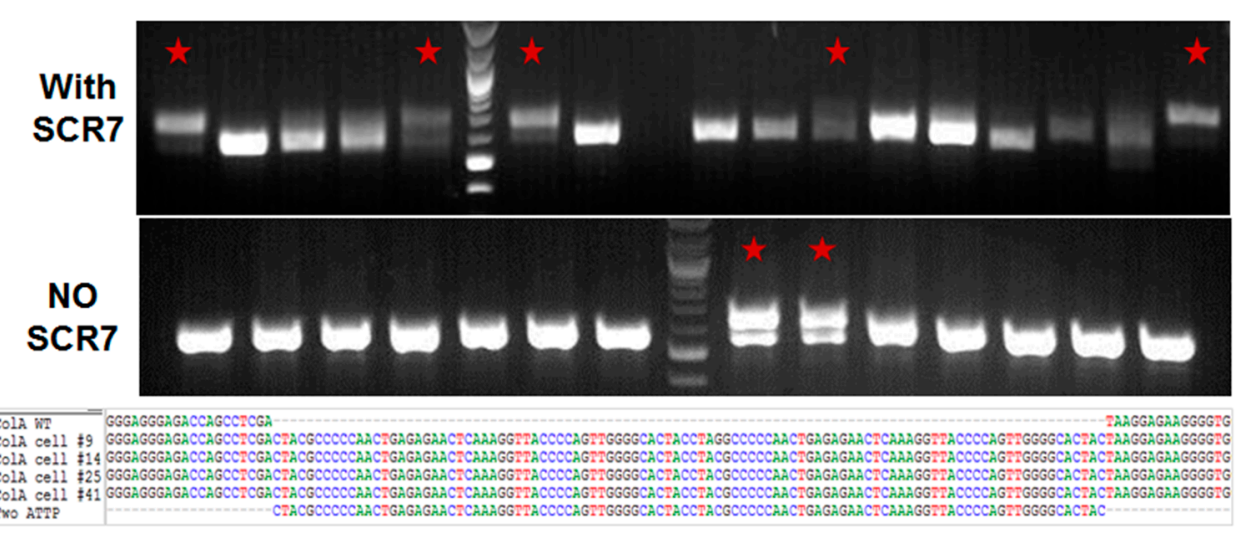

B. Cas9 plasmid + sgRNA DNA + Oligo at $38.5^{\circ} \mathrm{C}$

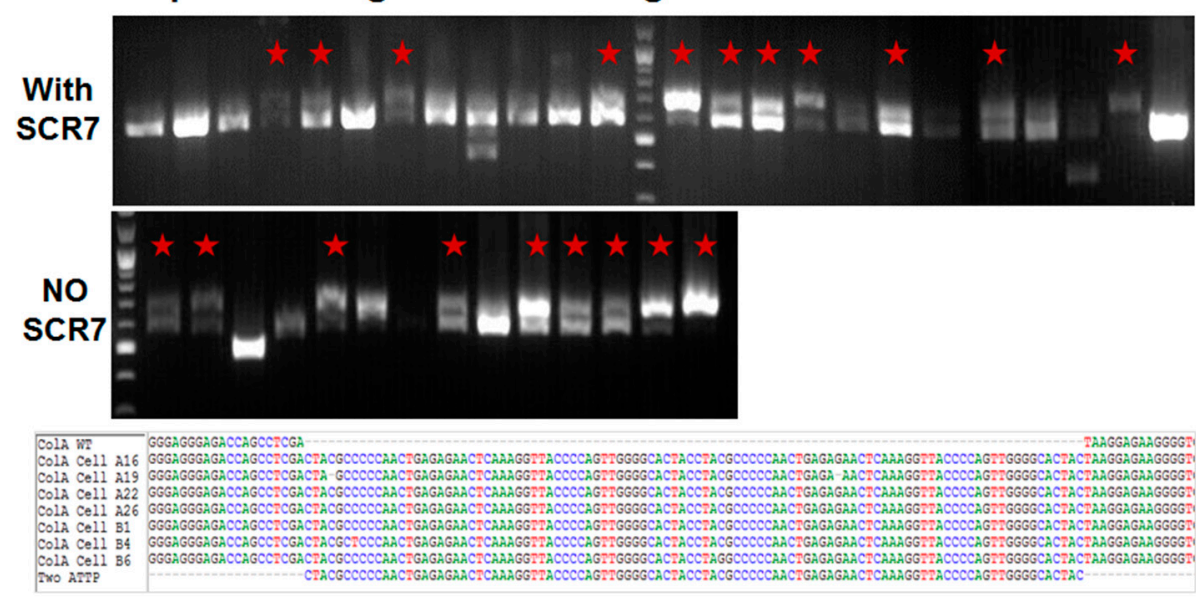

Figure 1. Cont. 

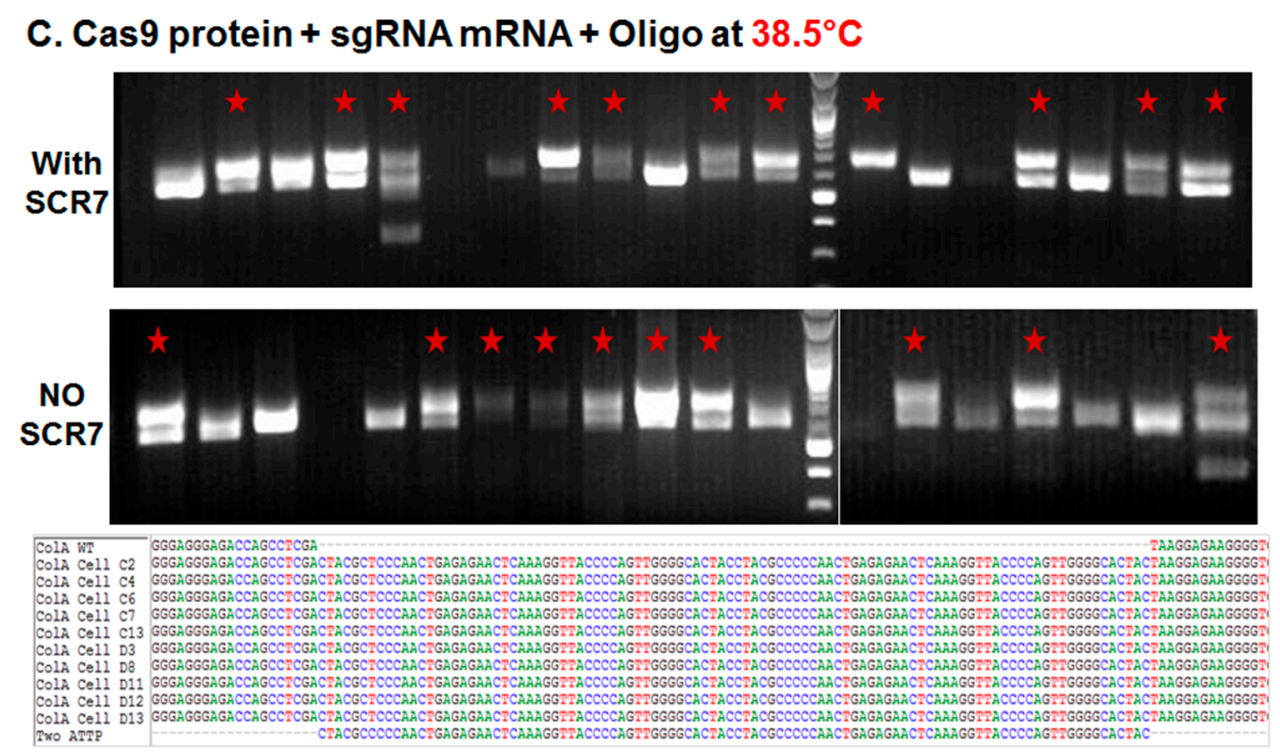

Figure 1. Targeted knockin of two pseudo attP sites $(100 \mathrm{bp})$ downstream of the porcine COL1A locus. (A-C) Agarose gel electrophoresis analysis of amplicons generated by primers bordering the COL1A targeting site. PCR amplicons of representative colonies derived from plasmid transfection and transient incubation at $30^{\circ} \mathrm{C}(\mathbf{A})$ or $38.5^{\circ} \mathrm{C}(\mathbf{B})$; and ribonucleoprotein $(\mathbf{C})$ transfection and culture at $38.5^{\circ} \mathrm{C}$. In each panel, representative colonies showing a new band with predicted shift of $100 \mathrm{bp}$ on the agarose gel produced by successful targeting and introgression of the two pseudo attP sites is marked by a red star. In each panel, the top row represents knockin in the presence of SCR7, the middle row without SCR7 and the bottom row represents Sanger sequencing of the amplicon. Multiple sequence alignment of wild type (WT) COL1A gene and two pseudo attP knockin sites are shown. Each nucleotide is color coded.

Table 1. Summary of CRISPR/Cas knockin experiments.

\begin{tabular}{|c|c|c|c|c|c|c|c|}
\hline $\begin{array}{l}\text { Cas9 \& sgRNA } \\
\text { Combination }\end{array}$ & $\begin{array}{l}\text { Treatment } \\
\text { with } \\
\text { SCR7 }\end{array}$ & $\begin{array}{c}\text { Initial } \\
\text { Culture } \\
\text { Temperature }\end{array}$ & $\begin{array}{l}\text { Number of } \\
\text { Single Cell } \\
\text { Sorted Wells }\end{array}$ & $\begin{array}{l}\text { Number of } \\
\text { Colonies } \\
\text { Formed }\end{array}$ & $\begin{array}{l}\% \text { of Colonies } \\
\text { Formed/Sorted } \\
\text { Wells }\end{array}$ & $\begin{array}{l}\text { Number of } \\
\text { Targeted } \\
\text { Colonies }\end{array}$ & $\begin{array}{c}\text { Percentage of Targeted } \\
\text { Colonies/Colonies } \\
\text { Formed }\end{array}$ \\
\hline Plasmid & None & $30^{\circ} \mathrm{C}$ & 960 & 16 & $1.70 \%$ & 2 & $13 \%$ \\
\hline Plasmid & SCR7 & $30{ }^{\circ} \mathrm{C}$ & 960 & 41 & $4.30 \%$ & 18 & $44 \%$ \\
\hline Plasmid & None & $38.5^{\circ} \mathrm{C}$ & 376 & 14 & $3.70 \%$ & 8 & $57 \%$ \\
\hline Plasmid & SCR7 & $38.5^{\circ} \mathrm{C}$ & 376 & 39 & $10.40 \%$ & 17 & $44 \%$ \\
\hline Ribonucleoprotein & None & $38.5^{\circ} \mathrm{C}$ & 376 & 58 & $15.40 \%$ & 18 & $31 \%$ \\
\hline Ribonucleoprotein & SCR7 & $38.5^{\circ} \mathrm{C}$ & 376 & 61 & $16.20 \%$ & 19 & $31 \%$ \\
\hline
\end{tabular}

\subsubsection{Comparison of Cas9:GFP/sgRNA Plasmid versus Ribonucleoprotein Delivery}

As noted above, incubation of plates at $38.5{ }^{\circ} \mathrm{C}$ resulted in a greater number of established colonies. In order to compare the targeting efficiencies between plasmid and protein cocktail, porcine somatic cells were nucleofected with Cas9 ribonucleoprotein complexes (targeting the same site) and plated at $38.5^{\circ} \mathrm{C}$ with or without SCR7 supplementation. When compared to plasmid delivery, nucleofection of Cas9 ribonucleoprotein complex resulted in a fourfold and 1.5-fold increases in the percentage of established colonies in the absence and presence of SCR7 (3.7\% vs. $15.4 \%$ and $10.4 \%$ vs. $16.2 \%$ ), respectively (Figure $1 \mathrm{C}$ and Table 1 ). Even though we found more colonies with the use of Cas9 ribonucleoproteins, the fraction of targeted colonies were not higher than plasmid transfections ( $31 \%$ vs. $57 \%$ or $44 \%$ ).

\subsection{Somatic Cell Nuclear Transfer to Generate Clonal COL1A Targeted Fetuses and Fibroblast Lines}

One of the COL1A targeted lines generated by CRISPR/Cas knockin and confirmed by sequencing was used as a nuclear donor for SCNT for generating clonal lines. From one embryo transfer session, 
we have obtained 11 healthy fetuses (Figure 2A). Fetal fibroblast lines were established from four of the 11 fetuses. As expected, PCR-based genotypic analysis revealed that all four fetuses had a $100 \mathrm{bp}$ knockin and shift in size of bands as expected (Figure 2B), which was further confirmed by Sanger sequencing (Figure 2C).
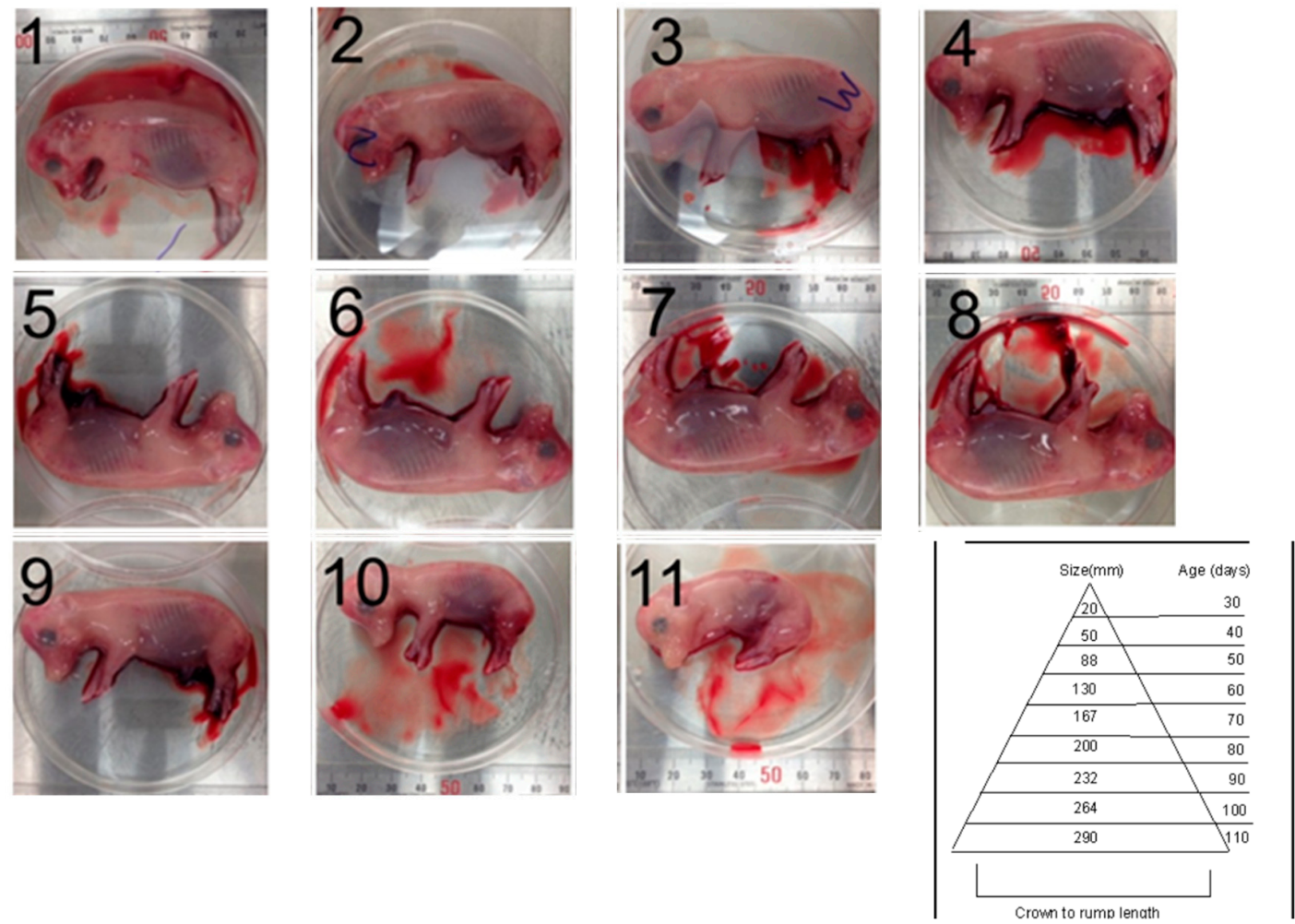

(A)

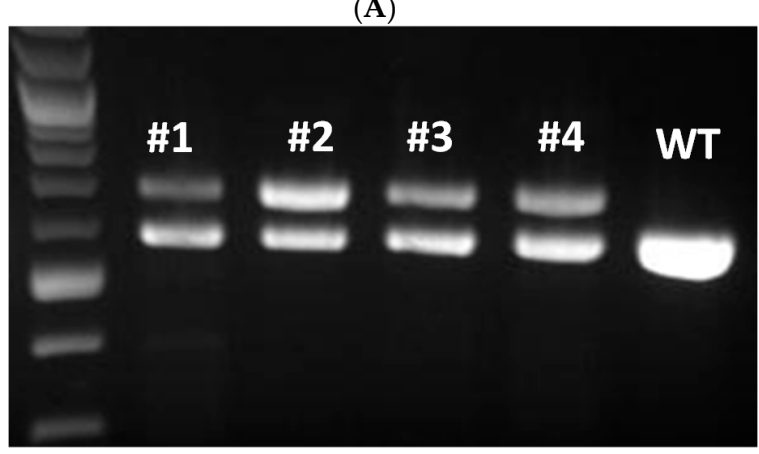

(B) GGGAGACCAGCCTCGA (B)

ColA NT fetus \#1 GGGGAGACCAGCCTCGA

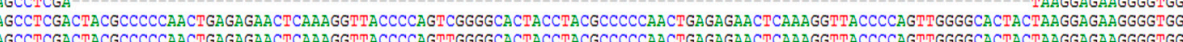

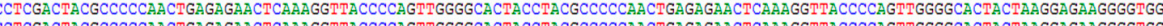
O ColA NT fetus \#4 GGG
Two ATTP

(C)

Figure 2. Somatic cell nuclear transfer (SCNT) of porcine COL1A targeted fetal fibroblast cells. (A) Photomicrograph depicts 11 clonal fetuses (numbered 1-11) at Day 45 of pregnancy along with a chart depicting crown-rump length and age of the fetus measure is shown; (B) Agarose gel electrophoresis image of COL1A amplicons from fetuses (numbered 1-4) on the top showing targeted knockin of the two attP sites and a $100 \mathrm{bp}$ shift in size. Amplicon from wildtype (WT) animal is shown as a reference; (C) Sanger sequencing of the clonal lines confirming the inclusion of the target sites. Multiple sequence alignment of wild type (WT) COL1A gene and two pseudo attP knockin sites are shown. Each nucleotide is color coded. 


\subsection{Phic31 Integrase Mediated Integration of Functional GFP Transgene into the attP Modified COL1A Locus}

One rationale for introducing attP sites downstream of the COL1A gene is to reproducibly and site-specifically introduce functional transgenes into attP sites using phiC31 integrase. A previously published GFP transgene containing phiC31 integrase consensus attB sites and G418 selection cassette, alongside cytomegalovirus promoter driven (CMV)-integrase expressing plasmid was nucleofected into COL1A targeted clonal line, and selected for stable integration by G418 selection [22,23]. Stable G418 resistant lines were selected by fluorescence-activated cell sorting (FACS) analysis, which showed integration at the attP sites in the COL1A locus (Figure 3). In the future, these sites will form the basis for knockin of other functional transgenes and generation of transgenic animals.

A
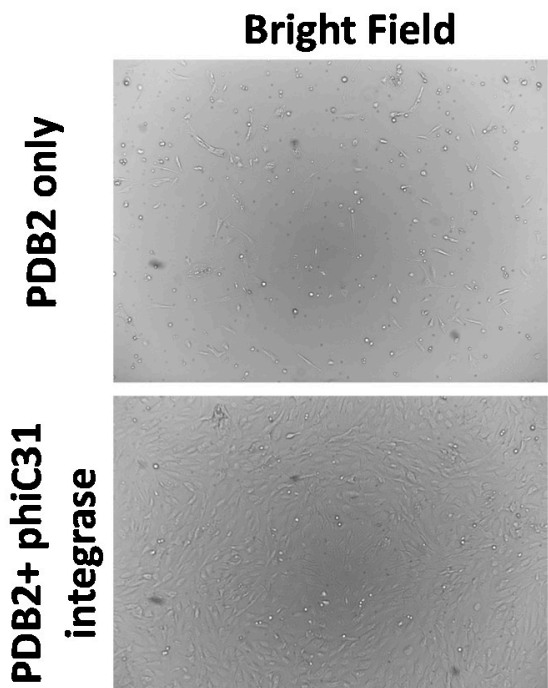

B

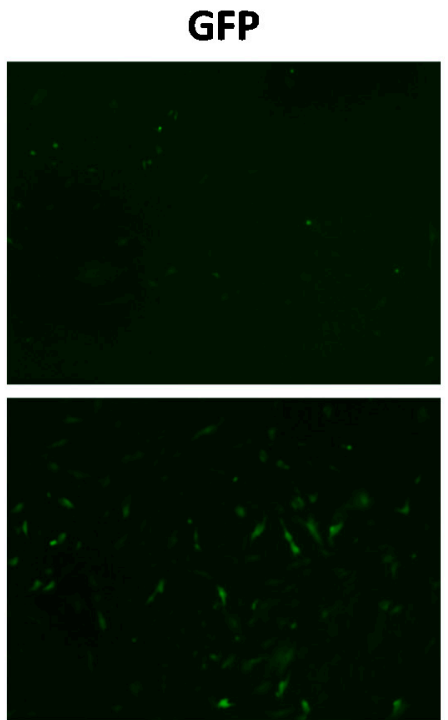

NA $\quad$ SA NB SB1 SB2 WT NO

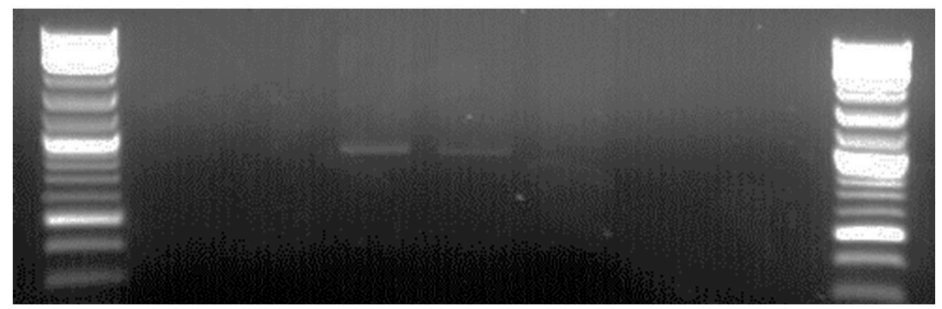

Figure 3. phiC31 integrase mediated integration of GFP transgene into COL1A targeted clonal lines. (A) Brightfield and fluorescent micrographs $(100 \times$ magnification) showing integration and expression of GFP transgene in COL1A knockin lines in the absence (top panel) or presence of integrase (bottom panel); (B) PCR amplicons showing targeted knockin of GFP transgene into the target sites. The cells following nucleofection and G418 selection and sorting were analyzed by PCR. Amplicons that show knockin were identified only in the presence of integrase and not in vector only treatment, wild type parent cells and no-template controls.

\section{Discussion}

The pig is arguably one of the most valuable animal models for biomedical research as well as for animal biotechnology. That said, the use of pig as a biomedical model is just gaining traction due to widespread and successful adoption of genome editing technologies [8-13]. Among the editors, the CRISPR/Cas system has earned the front runner status and greater adoption by the scientific community primarily because of low costs and ease in design, assembly, and delivery. As we show here, sophisticated gene modifications such as knockins, in combination with knockouts and point mutations are easier to achieve in somatic cells by engineering targeted DSBs using CRISPRs. 
In this manuscript, we sought to standardize procedures for routine gene targeting and creating a platform for site-specific integration of transgenes using CRISPR/Cas system. First we tested whether transient culture in low temperature promotes HDR as was previously reported $[18,19]$. In this study, we have not identified any advantage by culturing in low temperatures. There was a greater than twofold reduction in the number of colonies established at $30^{\circ} \mathrm{C}$ as compared to $38.5^{\circ} \mathrm{C}$ (the temperature at which porcine somatic cells are routinely cultured, presumably due to a lag in cell cycle). The use of SCR7, the inhibitor of NHEJ pathway enhanced colony formation and consequently the efficiency of gene targeting by greater than threefold at $30^{\circ} \mathrm{C}$. Likewise, at $38.5^{\circ} \mathrm{C}$ using plasmid transfection, SCR7 increased the number of colonies by three fold; however, the percentage of targeted lines was not different. Clearly, SCR7 solution had a noticeable effect on clonogenicity, however control experiments with just the solvent (DMSO) is lacking to definitively conclude that SCR7 improves clonogenicity. In this manuscript, we also demonstrated that the use of CRISPR ribonucleoproteins is effective, with greater than 1.5-fold increase in the number of colonies established. In the latter case, however, there was no noticeable difference when using SCR7 in either the number of colonies established or the targeting efficiencies. With a noticeable improvement in the number of robustly growing colonies and greater than 30\% targeting in the established clones, we argue that CRISPR ribonucleoprotein complex delivery is an effective means for gene targeting experiments. The two main advantages with this approach are: (1) high clonogenicity, requiring seeding and culture in fewer plates potentially making it less labor intensive; and (2) high reproducibility, as the CRISPR reagents are commercially available avoiding differences in reagent preparation between individual investigators. Additionally, with the availability of pseudo attP knockin fibroblast lines, we created a platform for stable integration of transgenes and generation of transgenic animals. Future investigations will be aimed at fine tuning the concentrations of attB containing donor vector and integrase plasmids, sorting the cells into single cells, and identify the percentage of integration of transgene into the attP knockin sites. We believe that this work represents an important step forward in achieving routine targeted genetic modifications in pigs.

\section{Materials and Methods}

All chemicals were obtained from Sigma Chemical Company (St. Louis, MO, USA) unless stated otherwise.

\subsection{Plasmid Construction and Production of sgRNA}

Expression plasmid for Cas9 nuclease (pMJ920) was a gift from Jennifer Doudna (Addgene plasmid \#42234) [24]. Targeting guide RNAs were designed based on the software available from MIT (Available online: http://www.genome-engineering.org/crispr/). Two complementary sgRNA oligo DNAs (22 nucleotides in length) were commercially synthesized (IDT DNA Technologies, Coralville, IA, USA), annealed to form double-strand DNA and cloned into a Bsa1 restriction enzyme digested in-house vector to yield a U6 promoter driven sgRNA expression cassette. The cloned fragments were DNA sequenced to confirm their fidelity. Confirmed sgRNA expressing vector was in vitro transcribed using MEGAshortscript T7 kit (Life Technologies, Carlsbad, CA, USA) to generate chimeric sgRNA. sgRNA was purified with MEGAclear kit (Life Technologies, CA, USA) for complexing with Cas9 protein prior to nucleofection.

\section{Nucleofection and Knockin Experiments}

Cas9 plasmid + sgRNA DNA + oligo or Cas9 protein + sgRNA mRNA + oligo were prepared to a final volume of less than $5 \mu \mathrm{L}$. The Cas9 protein mixture was incubated for $10 \mathrm{~min}$ at room temperature to allow ribonucleoprotein complex formation as per manufacturer's recommendation (Thermo Fisher Scientific, Waltham, MA, USA). Approximately, $1 \times 10^{6}$ cultured fetal fibroblast cells (culture conditions described below as for sorted cells) were harvested, washed once in PBS, and resuspended in nucleofection buffer (Lonza, Basel, Switzerland). About $5 \mu \mathrm{L}$ of Cas9 plasmid mixture 
or Cas9 protein mixture, and cell suspension were combined in a Lonza 4D strip nucleocuvette. Reaction mixtures were electroporated using DO113 setting and immediately plated into one well of a 6-well plate at high density to facilitate recovery. Electroporated cells were incubated (with $10 \mu \mathrm{M} / \mathrm{mL}$ SCR7 or without SCR7) $30{ }^{\circ} \mathrm{C}$ for $72 \mathrm{~h}$ or $38.5^{\circ} \mathrm{C}$ for 18 hand disassociated with $0.05 \%$ trypsin for sorting.

\subsection{Single Cell Sorting and Culture For Colony Screening}

Nucleofected cells were sorted for GFP expression on a BD Flowcytometer (San Jose, CA, USA) at the University of Maryland Flowcytometry Core at 1 cell/well density into 96-well plates, which were gelatinized by adding $100 \mu \mathrm{L}$ of $0.1 \%$ gelatin solution for $1-3 \mathrm{~h}$ to facilitate attachment. Fifty microliters of $40 \%$ FCS High Glucose DMEM which was conditioned (CM) by incubating $20 \mathrm{~mL}$ with $2.5 \times 10^{6}$ irradiated CF1 mouse embryonic feeder cells/T75 flask. The CM was supplemented with $5 \mathrm{ng} / \mu \mathrm{L}$ bFGF and filtered before adding to 96 well plate. All wells were fed with $50 \mu \mathrm{L} 10 \%$ FCS CM + bFGF immediately after sort, and $50 \mu \mathrm{L} \mathrm{20 \%} \mathrm{FCS} \mathrm{CM} \mathrm{after} 18 \mathrm{~h}$. The sorted plates were incubated in $5 \% \mathrm{CO}_{2}+5 \% \mathrm{O}_{2} 38.5^{\circ} \mathrm{C}$ for $7-10$ days. Colonies that were $80 \%-100 \%$ confluent were split with $0.05 \%$ Trypsin, with one well split into 2 wells of 48 well (1:4; this is passage (P1)) and further incubated at $38.5^{\circ} \mathrm{C}$ for $3-5$ days when 1 well was collected for DNA and the 2nd split into 1 well of 12 well (1:4) for further propagation (P2) or frozen in $92 \%$ FCS and $8 \%$ DMSO.

\subsection{Somatic Cell Nuclear Transfer (SCNT)}

All animal work was performed as per the approved guidelines of Beltsville ARS, Institutional Animal Care and Use Committee. SCNT was performed as described in previous study [25]. Cumulus-oocyte complexes (COCs) were purchased from a commercial supplier (De Soto Biosciences, Seymour, TN, USA). Briefly, matured oocytes were enucleated by aspirating the polar body and MII chromosomes with an enucleation pipette (Humagen, Charlottesville, VA, USA). After enucleation, a donor cell was introduced into the perivitelline space of an enucleated oocyte. Fusion of injected oocytes was induced by DC pulse $(2.0 \mathrm{kV} / \mathrm{cm}$ for $30 \mu$ s using a BTX-Cell Manipulator 2001 (BTX, San Diego, CA, USA)). After fusion, the reconstructed oocytes were activated by an electric pulse $(1.0 \mathrm{kV} / \mathrm{cm}$ for $60 \mu \mathrm{s})$, followed by $4 \mathrm{~h}$ of incubation in PZM3 medium containing $2 \mathrm{mM}$ 6-dimethylaminopurine. Approximately 120-130 reconstructed oocytes were surgically transferred into the oviducts of naturally cycling gilts on the first day of standing estrus. Following transfer, pregnancies were confirmed on Day 30 by ultrasound. Fetuses were harvested from Day 45 pregnant euthanized sow. Tissues from four of the 11 fetuses were trypsin digested and incubated in T175 plates (P0) for subsequent culture and cryostorage.

\subsection{Genotyping of Fibroblast Cell Colonies, and Edited Nuclear Transfer Fetuses}

Single cell derived colonies cultured for 10-15 days were washed three times with PBS-PVA (pH 7.4) medium. About 2-3 $\mu \mathrm{L}$ of colony suspension was transferred into $18 \mu \mathrm{L}$ of colony lysis buffer $(50 \mathrm{mM} \mathrm{KCl}, 1.5 \mathrm{mM} \mathrm{MgCl} 2,10 \mathrm{mM}$ Tris $\mathrm{pH}$ 8.0, $0.5 \% \mathrm{NP}-40,0.5 \%$ Tween-20 and $100 \mu \mathrm{g} / \mathrm{mL}$ proteinase $\mathrm{K}$ ) and incubated for $1 \mathrm{~h}$ at $65^{\circ} \mathrm{C}$. The digestion was terminated by heating the mixture at $95^{\circ} \mathrm{C}$ for $10 \mathrm{~min}$, and $2 \mu \mathrm{L}$ of supernatant was used as a PCR template. Tissue biopsies from fetuses were digested in a tissue lysis buffer (50 mM Tris pH 8.0, $0.1 \mathrm{M} \mathrm{NaCl}, 20 \mathrm{mM}$ EDTA, 1\% SDS, $50 \mu \mathrm{g} / \mathrm{mL}$ RNase A, $100 \mu \mathrm{g} / \mathrm{mL}$ proteinase $\mathrm{K}$ ) overnight at $65^{\circ} \mathrm{C}$. Following overnight digest, the genomic DNA of the sample was extracted from the tissue lysate using phenol-chloroform, and recovered by resuspension in $100 \mu \mathrm{L}$ of $10 \mathrm{mM}$ Tris- $\mathrm{HCl}, \mathrm{pH} 7.4$ buffer following ethanol precipitation. Purified genomic DNA was amplified using PCR (primers in Table 2), cloned into PCR2.1 vectors (Thermo Fisher Scientific, Waltham, MA, USA) and transformed into E. coli DH5- $\alpha$ maximum competent cells (Thermo Fisher Scientific). Five to ten colonies were picked, cultured, plasmid DNA extracted and sequenced (Macrogen, Rockville, MD, USA). Sequences were aligned by Bio-Edit software (Available online: 
http://www.mbio.ncsu.edu/BioEdit/bioedit.html) for comparison with wild-type and two attP sites per allele.

Table 2. Primers used in the manuscript.

\begin{tabular}{ccc}
\hline Target & Primer & Sequence \\
\hline \multirow{2}{*}{ Gene Knockin Primers } & COL1A Forward & AGCCAGGCTGCCTTGTTTG \\
\cline { 2 - 3 } & COL1A Reverse & GCCAACCTCCCCTTTGCACT \\
\hline \multirow{2}{*}{ pDB2 Integration Primers } & EGFPC & CATGGTCCTGCTGGAGTTCGTG \\
\cline { 2 - 3 } & COL1A Reverse & AGCCAGGCTGCCTTGTTTG \\
\hline
\end{tabular}

\subsection{Targeted phiC31 Integrase Mediated Integration of GFP Transgene into Pseudo attP Sites in COL1A Locus}

pDB2 and pCMV-Integrase plasmids were a gift from Michele Calos (Addgene plasmids \#18954 and 18935 respectively) [22,23]. Porcine fetal fibroblasts containing pseudo attP sites downstream of COL1A site were nucleofected with a previously published GFP transgene (pDB2; $0.7 \mu \mathrm{g})$ containing consensus attB site for phiC31 integrase and CMV promoter driven integrase gene (1.3 $\mu \mathrm{g})$ [26]. A control nucleofection was performed with GFP transgene (pDB2) without the CMV-Integrase plasmid. Following nucleofection, the cells were selected for stable integration by selecting with $500 \mathrm{ng} / \mu \mathrm{L}$ of G418 for 7-10 days followed by flow cytometry. A PCR screen was performed with transgene specific and flanking COL1A sequence to show integration of the plasmid at the target site (primers in Table 2).

Acknowledgments: We thank Agricultural Research Station (ARS) staff and attending veterinarian for help with animal work. Bhanu P. Telugu is supported by Genus plc and National Institute of Food and Agriculture (NIFA) Dual purpose with Dual Benefit Grant \#2015-67015-22845. David M. Donovan and Anne Powell are supported by ARS Project \#8042-31000-103-00D.

Author Contributions: Ki-Eun Park and Bhanu P. Telugu conceived and planned experiments. Anne Powell performed cell culture and FACS sorting. Chi-Hun Park performed SCNT. Ki-Eun Park and Jessica Martin performed genotyping and screening of targeted cells. Anne Powell and Bhanu P. Telugu synchronized the donor and recipient animals and performed embryo transfers. David M. Donovan provided technical discussions and support for both animal space and technical support. Ki-Eun Park, Anne Powell and Bhanu P. Telugu analyzed and evaluated data. Bhanu P. Telugu wrote the manuscript with critiques from all other authors. All authors reviewed and approved the manuscript.

Conflicts of Interest: Ki-Eun Park and Bhanu P. Telugu are founding members of Livestock Genomix. All other authors declare no competing financial interests.

\section{Abbreviations}

The following abbreviations are used in this manuscript:

$\begin{array}{ll}\text { CRISPR/Cas } & \text { Clustered regulated interspaced short palindromic repeat and CRISPR-associated (Cas) } \\ \text { SCNT } & \text { Suclease system } \\ \text { COL1A } & \text { Collagen 1A locus } \\ \text { DSB } & \text { Double strand break }\end{array}$

\section{References}

1. Whitelaw, C.B.; Sheets, T.P.; Lillico, S.G.; Telugu, B.P. Engineering large animal models of human disease. J. Pathol. 2016, 238, 247-256. [CrossRef] [PubMed]

2. Grubb, B.R.; Boucher, R.C. Pathophysiology of gene-targeted mouse models for cystic fibrosis. Physiol. Rev. 1999, 79, S193-S214. [PubMed]

3. Montier, T.; Delepine, P.; Pichon, C.; Ferec, C.; Porteous, D.J.; Midoux, P. Non-viral vectors in cystic fibrosis gene therapy: Progress and challenges. Trends Biotechnol. 2004, 22, 586-592. [CrossRef] [PubMed] 
4. Carvalho-Oliveira, I.; Scholte, B.J.; Penque, D. What have we learned from mouse models for cystic fibrosis? Expert Rev. Mol. Diagn. 2007, 7, 407-417. [CrossRef] [PubMed]

5. Wilke, M.; Buijs-Offerman, R.M.; Aarbiou, J.; Colledge, W.H.; Sheppard, D.N.; Touqui, L.; Bot, A.; Jorna, H.; de Jonge, H.R.; Scholte, B.J. Mouse models of cystic fibrosis: Phenotypic analysis and research applications. J. Cyst. Fibros. 2011, 10 (Suppl. 2), S152-S171. [CrossRef]

6. Park, K.E.; Telugu, B.P. Role of stem cells in large animal genetic engineering in the TALENs-CRISPR era. Reprod. Fertil. Dev. 2013, 26, 65-73. [CrossRef] [PubMed]

7. Moehle, E.A.; Rock, J.M.; Lee, Y.L.; Jouvenot, Y.; DeKelver, R.C.; Gregory, P.D.; Urnov, F.D.; Holmes, M.C. Targeted gene addition into a specified location in the human genome using designed zinc finger nucleases. Proc. Natl. Acad. Sci. USA 2007, 104, 3055-3060. [CrossRef] [PubMed]

8. Zhou, X.; Xin, J.; Fan, N.; Zou, Q.; Huang, J.; Ouyang, Z.; Zhao, Y.; Zhao, B.; Liu, Z.; Lai, S.; et al. Generation of CRISPR/Cas9-mediated gene-targeted pigs via somatic cell nuclear transfer. Cell. Mol. Life Sci. 2015, 72, 1175-1184. [CrossRef] [PubMed]

9. Zhou, X.; Wang, L.; Du, Y.; Xie, F.; Li, L.; Liu, Y.; Liu, C.; Wang, S.; Zhang, S.; Huang, X.; et al. Efficient generation of gene-modified pigs harboring precise orthologous human mutation via CRISPR/Cas9-induced homology-directed repair in zygotes. Hum. Mutat. 2016, 37, 110-118. [CrossRef] [PubMed]

10. Whitworth, K.M.; Lee, K.; Benne, J.A.; Beaton, B.P.; Spate, L.D.; Murphy, S.L.; Samuel, M.S.; Mao, J.; O'Gorman, C.; Walters, E.M.; et al. Use of the CRISPR/Cas9 system to produce genetically engineered pigs from in vitro-derived oocytes and embryos. Biol. Reprod. 2014, 91. [CrossRef] [PubMed]

11. Wang, X.; Zhou, J.; Cao, C.; Huang, J.; Hai, T.; Wang, Y.; Zheng, Q.; Zhang, H.; Qin, G.; Miao, X.; et al. Efficient CRISPR/Cas9-mediated biallelic gene disruption and site-specific knockin after rapid selection of highly active sgRNAs in pigs. Sci. Rep. 2015, 5. [CrossRef] [PubMed]

12. Wang, X.; Cao, C.; Huang, J.; Yao, J.; Hai, T.; Zheng, Q.; Wang, X.; Zhang, H.; Qin, G.; Cheng, J.; et al. One-step generation of triple gene-targeted pigs using CRISPR/Cas9 system. Sci. Rep. 2016, 6. [CrossRef] [PubMed]

13. Chen, F.; Wang, Y.; Yuan, Y.; Zhang, W.; Ren, Z.; Jin, Y.; Liu, X.; Xiong, Q.; Chen, Q.; Zhang, M.; et al. Generation of B cell-deficient pigs by highly efficient CRISPR/Cas9-mediated gene targeting. J. Genet. Genomics 2015, 42, 437-444. [CrossRef] [PubMed]

14. Jinek, M.; Chylinski, K.; Fonfara, I.; Hauer, M.; Doudna, J.A.; Charpentier, E. A programmable dual-RNA-guided DNA endonuclease in adaptive bacterial immunity. Science 2012, 337, 816-821. [CrossRef] [PubMed]

15. Lai, S.; Wei, S.; Zhao, B.; Ouyang, Z.; Zhang, Q.; Fan, N.; Liu, Z.; Zhao, Y.; Yan, Q.; Zhou, X.; et al. Generation of knock-in pigs carrying oct4-tdtomato reporter through CRISPR/Cas9-mediated genome engineering. PLoS ONE 2016, 11, e0146562. [CrossRef] [PubMed]

16. Maruyama, T.; Dougan, S.K.; Truttmann, M.C.; Bilate, A.M.; Ingram, J.R.; Ploegh, H.L. Increasing the efficiency of precise genome editing with CRISPR-Cas9 by inhibition of nonhomologous end joining. Nat. Biotechnol. 2015, 33, 538-542. [CrossRef] [PubMed]

17. Chu, V.T.; Weber, T.; Wefers, B.; Wurst, W.; Sander, S.; Rajewsky, K.; Kuhn, R. Increasing the efficiency of homology-directed repair for CRISPR-Cas9-induced precise gene editing in mammalian cells. Nat. Biotechnol. 2015, 33, 543-548. [CrossRef] [PubMed]

18. Doyon, Y.; Choi, V.M.; Xia, D.F.; Vo, T.D.; Gregory, P.D.; Holmes, M.C. Transient cold shock enhances zinc-finger nuclease-mediated gene disruption. Nat. Methods 2010, 7, 459-460. [CrossRef] [PubMed]

19. Miller, J.C.; Tan, S.; Qiao, G.; Barlow, K.A.; Wang, J.; Xia, D.F.; Meng, X.; Paschon, D.E.; Leung, E.; Hinkley, S.J.; et al. A tale nuclease architecture for efficient genome editing. Nat. Biotechnol. 2011, 29, 143-148. [CrossRef] [PubMed]

20. Brown, W.R.; Lee, N.C.; Xu, Z.; Smith, M.C. Serine recombinases as tools for genome engineering. Methods 2011, 53, 372-379. [CrossRef] [PubMed]

21. Smith, M.C.; Brown, W.R.; McEwan, A.R.; Rowley, P.A. Site-specific recombination by phiC31 integrase and other large serine recombinases. Biochem. Soc. Trans. 2010, 38, 388-394. [CrossRef] [PubMed]

22. Keravala, A.; Portlock, J.L.; Nash, J.A.; Vitrant, D.G.; Robbins, P.D.; Calos, M.P. PhiC31 integrase mediates integration in cultured synovial cells and enhances gene expression in rabbit joints. J. Gene Med. 2006, 8, 1008-1017. [CrossRef] [PubMed]

23. Groth, A.C.; Olivares, E.C.; Thyagarajan, B.; Calos, M.P. A phage integrase directs efficient site-specific integration in human cells. Proc. Natl. Acad. Sci. USA 2000, 97, 5995-6000. [CrossRef] [PubMed] 
24. Jinek, M.; East, A.; Cheng, A.; Lin, S.; Ma, E.; Doudna, J. RNA-programmed genome editing in human cells. eLife 2013, 2, e00471. [CrossRef] [PubMed]

25. Jeong, Y.H.; Park, C.H.; Jang, G.H.; Jeong, Y.I.; Hwang, I.S.; Jeong, Y.W.; Kim, Y.K.; Shin, T.; Kim, N.H.; Hyun, S.H.; et al. Production of multiple transgenic yucatan miniature pigs expressing human complement regulatory factors, human CD55, CD59, and H-transferase genes. PLoS ONE 2013, 8, e63241.

26. Luo, Y.; Wang, Y.; Liu, J.; Lan, H.; Shao, M.; Yu, Y.; Quan, F.; Zhang, Y. Production of transgenic cattle highly expressing human serum albumin in milk by phiC31 integrase-mediated gene delivery. Transgenic Res. 2015, 24, 875-883. [CrossRef] [PubMed]

(C) 2016 by the authors; licensee MDPI, Basel, Switzerland. This article is an open access article distributed under the terms and conditions of the Creative Commons Attribution (CC-BY) license (http://creativecommons.org/licenses/by/4.0/). 